\title{
PIK3CA oncogenic mutations represent a major mechanism of resistance to trastuzumab in HER2/neu overexpressing uterine serous carcinomas
}

\author{
Jonathan D Black ${ }^{1}$, Salvatore Lopez ${ }^{1,2}$, Emiliano Cocco ${ }^{1}$, Stefania Bellone ${ }^{1}$, Gary Altwerger ${ }^{1}$, \\ Carlton L Schwab ${ }^{1}$, Diana P English ${ }^{1}$, Elena Bonazzoli ${ }^{1}$, Federica Predolini ${ }^{1}$, Francesca Ferrari ${ }^{1}$, Elena Ratner ${ }^{1}$, \\ Dan-Arin Silasi ${ }^{1}$, Masoud Azodi ${ }^{1}$, Peter E Schwartz ${ }^{1}$ and Alessandro D Santin ${ }^{*}, 1$ \\ ${ }^{1}$ Department of Obstetrics, Gynecology and Reproductive Sciences Yale University School of Medicine, Yale, CT 06520, USA and \\ ${ }^{2}$ Division of Gynecologic Oncology, Department of Obstetrics and Gynecology, University Campus Bio-Medico of Rome, Via \\ Alvaro del Portillo 21, 00128 Rome, Italy
}

Objectives: We evaluated the role of PIK3CA-mutations as mechanism of resistance to trastuzumab in primary HER2/neuamplified uterine-serous-carcinoma (USC) cell lines.

\begin{abstract}
Methods: Fifteen whole-exome-sequenced USC cell lines were tested for HER2/neu-amplification and PIK3CA-mutations. Four HER2/neu-amplified USC (2-harbouring wild-type-PIK3CA-genes and 2-harbouring oncogenic-PIK3CA-mutations) were evaluated in in vitro dose-titration-proliferation-assays, cell-viability and HER2 and S6-protein-phosphorylation after exposure to trastuzumab. USC harbouring wild-type-PIK3CA were transfected with plasmids encoding oncogenic PIK3CA-mutations (i.e., H1047R/R930) and exposed to trastuzumab. Finally, trastuzumab efficacy was tested by using two USC xenograft mouse models.

Results: Seven out of fifteen (46\%) of the USC cell lines were HER2/neu-amplified by fluorescence in situ hybridisation. Within these tumours four out of seven (57\%) were found to harbour oncogenic PIK3CA-mutations vs two out of eight (25\%) of the HER2/neu not amplified cell lines $(P=0.01)$. HER2/neu-amplified/PIK3CA-mutated USC were highly resistant to trastuzumab when compared with HER2/neu-amplified/wild-type-PIK3CA cell lines $(P=0.02)$. HER2/neu-amplified/PIK3CA wild-type cell lines transfected with oncogenic PIK3CA-mutations increased their resistance to trastuzumab $(P<0.0001)$. Trastuzumab was effective in reducing tumour growth $(P=0.001)$ and improved survival $(P=0.0001)$ in mouse xenografts harbouring HER2-amplified/PIK3CA wild-type USC but not in HER2-amplified/PIK3CA-mutated tumours.
\end{abstract}

Conclusions: Oncogenic PIK3CA mutations are common in HER2/neu-amplified USC and may constitute a major mechanism of resistance to trastuzumab treatment.

Endometrial cancer is the most common gynaecologic malignancy in women in the United States and accounts for $6 \%$ of cancers in women worldwide. In the United States in 2015, 54870 women will be diagnosed with endometrial cancer and 10170 women will succumb to the disease (Siegel et al, 2015).
Endometrial cancer is classified into two subtypes (Bokhman, 1983). Type I endometrial cancers are associated with endometrioid histology, typically low grade and early stage, are estrogendependent, and are associated with high overall survival (OS). Type II endometrial cancers, on the other hand, are estrogen- 
independent, of serous, clear-cell or grade 3 endometrioid histology, often associated with advanced stage at the time of diagnosis, exhibit an aggressive clinical course and are associated with poor OS. Notably, 52-70\% of type II cancers exhibit extrauterine spread at the time of surgery, compared with $4.6 \%$ of Type I tumours (Goff, 2005; Thomas et al, 2008; Yoon et al, 2010). Uterine-serous-carcinoma (USC), is the most biologically aggressive Type II tumour, accounts for $10 \%$ of all endometrial cancer and carries the poorest prognosis, with 5-year survival rates as low as $55 \%$ (Hamilton et al, 2006).

The $c$-erbB2 gene is a member of the erbB receptor tyrosine kinase family, which consists of four transmembrane glycoproteins: erbB1, erbB2, erbB3 and erbB4. The c-erbB2 gene encodes erbB2 (HER2). When HER2 is amplified, the tyrosine kinase becomes constitutively active thereby increasing phosphorylation of intracellular tyrosine kinase residues and ultimately increasing cell proliferation, differentiation, migration and survival (Hynes and Stern, 1994; Okines et al, 2011). In endometrial carcinoma, HER2 overexpression has been reported between 4 and 69\% (Peiro et al, 2004) and is significantly more common in Type II endometrial tumours (Morrison et al, 2006; Villella et al, 2006; English et al, 2013a,b). USC has the highest rates of expression among the endometrial cancers; up to $35 \%$ of tumours harbour HER2 gene amplification (Morrison et al, 2006; Villella et al, 2006; English et al, 2013b).

Trastuzumab, a humanised monoclonal antibody targeting the HER2 receptor, is endowed with remarkable clinical activity in breast cancer patients with HER2 amplification (Slamon et al, 2001; Verma et al, 2012). The clinical activity of trastuzumab relies on the prevention of the heterodimerisation of HER2 receptor with the other members of the EGF receptor family (HER1, HER3 and HER4) and abrogation of downstream effectors as well as through recruitment of natural killer cells and initiation of antibodydependent cell-mediated cytotoxicity or complement-dependent cytotoxicity, resulting in tumour lysis (Gennari et al, 2004; Arnould et al, 2006). Because of the common overexpression of the HER2 receptor in USC, trastuzumab may represent a potentially effective therapeutic agent against chemotherapy-resistant/recurrent USC. However, the results of Phase II trials from the Gynecologic Oncology Group (i.e., GOG 181B) using single agent trastuzumab in recurrent HER2-positive endometrial cancer patients have been disappointing (Fleming et al, 2010). Although it is currently not understood why endometrial cancer patients overexpressing HER2 differ in their response to trastuzumab from breast cancer patients, these negative results suggest an inborn or rapidly acquired resistance to trastuzumab in USC.

The PIK3CA/AKT/mTOR signalling cascade is critical to diverse cellular responses, including cell proliferation, survival, metabolism, and control of malignant cellular growth (Dancey, 2006). HER2/neu is located upstream to the PIK3CA/AKT/mTOR pathway (English et al, 2013c). HER2/neu and the PIK3CA/AKT/ mTOR pathway can be constitutively activated secondary to gene amplifications (i.e., HER2/neu) or activating mutations in the PIK3CA/AKT genes (She et al, 2008; Brachmann et al, 2009). Importantly, multiple research groups, including our own, have recently reported PIK3CA gene mutations and HER2/neu gene amplifications in a relevant number of biologically aggressive endometrial cancers by whole-exome sequencing (Le Gallo et al, 2012; Zhao et al, 2013).

Our study aimed to better understand the role of PIK3CA mutations in HER2 overexpressing USC cell lines when treated with trastuzumab.

\section{MATERIAL AND METHODS}

USC cell lines. Specimens were obtained from fresh tumour biopsies at the time of surgery, under approval of the institutional review board. USC cell lines were established as previously described (English et al, 2013b). Tumour HER2/neu gene amplification was evaluated by fluorescence in situ hybridisation (FISH), while PIK3CA gene mutations were evaluated by wholeexome sequencing as previously described by our group (English et al, 2013b). Of the 15 primary cell lines previously evaluated, four were selected, as seen in Table 1, for the additional in vitro and in vivo experiments with trastuzumab. The four USC cell lines have similar growth rates and demonstrated similar erbB2 gene amplification by FISH but differ in their PIK3CA status. ARK-2 and ARK-21 harboured a wild-type PIK3CA gene while ARK-1 and ARK-20 harboured oncogenic PIK3CA mutations (i.e., E542K and H1047R, respectively, Table 1).

Transfection experiments with USC cell lines. Full-length, wildtype and mutated (R93Q and H1047R mutations of PIK3CA p110, (a kind gift from Dr Daphne Bell, NIH) (Rudd et al, 2011) cDNA were cloned into the pFastBac vector (Invitrogen, Waltham, MA, USA). Briefly, the Escherichia coli strain BL21 (DE3) (Agilent Technologies, Santa Clara, CA, USA) was transformed with these vectors. The transformed cells were grown in LB broth containing $100 \mu \mathrm{g} \mathrm{ml}^{-1}$ ampicillin. After expansion, the plasmid DNA was purified by the QIAGEN (Valencia, CA, USA) plasmid kit according to the manufacturer instruction. ARK-2 cells were then transfected with oncogenic (activating) PIK3CA constructs using the FuGENE-6 transfection reagent (Roche, South San Francisco, CA, USA), according to the manufacturer's protocol. In a similar fashion, ARK-2 cells were transfected with empty plasmids with the same protocol. Stably transfected cells were selected in the presence of $600 \mathrm{mg} \mathrm{ml}^{-1} \mathrm{G} 418$ (Invitrogen).

Drug. Trastuzumab (Genentech, South San Francisco, CA, USA) was dissolved in phosphate buffered saline (PBS) (Life Technologies, Waltham, MA, USA) as a $20 \mathrm{mg} \mathrm{ml}^{-1}$ stock solution and diluted immediately before use.

Chemoresponse assay. The effect of trastuzumab on the viability of cells as well as the $\mathrm{IC}_{50}$, was determined using a previously characterised flow cytometry assay based on propidium iodide (English et al, 2014d). Tumour cells derived from the four primary USC cell lines (two cell lines harbouring HER2/neu gene amplifications with PIK3CA mutations and two cell lines harbouring HER2/neu gene amplifications wild-type PIK3CA) as well as the transfected cell lines were plated in six-well tissue culture plates. When tumour cells were at exponential growth, they were treated with trastuzumab at concentrations of $0.01,0.05,0.1$, $0.5,1,2,5,10,20,40,100 \mu \mathrm{g} \mathrm{ml}^{-1}$. After 6 days of incubation, well contents were harvested in their entirety using $0.05 \%$ Trypsin EDTA (Invitrogen), centrifuged and then stained with propidium iodide $\left(2 \mu \mathrm{l}\right.$ of a $500 \mathrm{mg} \mathrm{ml}^{-1}$ stock solution in PBS with $0.1 \%$ sodium azide and $2 \%$ fetal bovine serum) for flow cytometric counts. Viable cells were then quantified using FACSCalibur and Cell Quest software (BD Biosciences, San Jose, CA, USA) as percent of viable cells (mean \pm s.e.m.) vs $100 \%$ untreated controls. A minimum of three independent experiments per USC cell line were performed.

Table 1. Cell line characteristics
\begin{tabular}{|l|c|c|c|c|c|c|}
\hline Cell line & Age & Race & Stage & $\begin{array}{c}\text { C-erbB2 } \\
\text { FISH }\end{array}$ & IHC & $\begin{array}{c}\text { PIK3CA } \\
\text { mutations } \\
\text { exon 9, 20 }\end{array}$ \\
\hline ARK-1 & 62 & B & IV & Amplified & $3+$ & $542 / 1068$ \\
\hline ARK-2 & 63 & B & IV & Amplified & $3+$ & Not detected \\
\hline ARK-20 & 42 & W & II & Amplified & $3+$ & $1047 / 1068$ \\
\hline ARK-21 & 70 & W & IA & Amplified & $3+$ & Not detected \\
\hline Abbreviations: FISH = fluorescence in situ hybridisation; IHC =immunohistochemistry. \\
\hline
\end{tabular}


Flow cytometry analysis of phosphorylated S6 and phosphorylated HER2 intracellular levels in primary USC cell lines. A previously validated flow cytometry-based assay was used to evaluate the baseline level as well as the change in phosphorylated HER2 and S6 expression as a downstream cellular response to trastuzumab in USC cell lines. After $24 \mathrm{~h}$ exposure to $40 \mu \mathrm{g} \mathrm{ml}^{-1}$ of trastuzumab, well contents were harvested in their entirety using 0.05\% Trypsin EDTA (Invitrogen). Cells were fixed using 4\% paraformaldehyde for $10 \mathrm{~min}$ at $37^{\circ} \mathrm{C}$ and then washed with PBS and permeabilised with $90 \%$ methanol for $30 \mathrm{~min}$. They were then suspended in incubation buffer (PBS containing 0.5\% BSA), blocked for $10 \mathrm{~min}$, and aliquoted into three tubes. Cells were allowed to incubate with primary rabbit monoclonal antibodies: phospho-HER2/ErbB2 (Y1221/1222 Cell Signaling Technologies, Inc., Danvers, MA, USA), Phospho-S6 Ribosomal Protein (Ser235/236 Cell Signaling Technology, Inc.) and no primary antibody for one hour on ice. Cells were then washed in incubation buffer two times and allowed to incubate with fluorescein conjugated goat anti-rabbit immunoglobulin (AQ132F) secondary fluorescein conjugated antibody (Millipore, Temecula, CA, USA) for half an hour on ice. Samples were then washed, suspended in PBS, and read by flow cytometry. Cells (i.e., 10000 events per sample) were analysed on FACSCalibur, using Cell Quest software (BD Biosciences). Differences in mean intensity of fluorescence (MFI) and percentage gated cells between groups and treatments were then compared.

Western blot analysis of HER2, pHER2, S6 and pS6 in PI3KCAtransfected ARK-2 USC cells. USPC-ARK-2 cells transfected with the plasmids encoding for the oncogenic PI3KCA mutation H1047R and R93Q were selected and grown in medium containing G418 $(600 \mu \mathrm{g}-\mathrm{ml})$. H1047R and R93Q ARK-2 cells were then washed and mechanically scraped and lysed on ice with RIPA buffer supplemented with protease inhibitor cocktail. Lysates were recovered after centrifugation and protein levels were quantified using a BCA Protein Assay Kit (\#23225, Thermo Scientific, Waltham, MA, USA). Samples were then loaded in equal amounts on $4-20 \%$ acrylamide precast gels (Bio-Rad, Waltham, MA, USA). Proteins were then transferred to polyvinylidene difluoride membranes (Bio-Rad) for the immunoblots. Antibodies used were HER2 (\#06562, Millipore), pHER2 (\#2247, Cell Signaling), GAPDH (\#2118, Cell Signaling), S6 (\#2217, Cell Signaling) and pS6 (\#5364, Cell Signaling). Incubation of the membranes with primary antibodies was performed overnight in $5 \%$ BSA/milk in PBS-Tween at $4{ }^{\circ} \mathrm{C}$. After incubation, membranes were washed three times with $1 \%$ milk in PBS-Tween (0.2\%) at room temperature and incubated with an HRP-linked secondary antibodies in 5\% milk PBS-Tween $(0.2 \%)$ for 1 hour before washing four times in $1 \%$ milk PBS-Tween. Signals were detected with western blotting detection reagents (Thermo Scientific). Bands were then visualised and the blots developed using an enhanced chemiluminescent system (GEL Logic 1500, Carestream Health, Inc., Rochester, NY, USA).

In vivo assay of drug effect. To determine the in vivo activity of trastuzumab, a representative PIK3CA-mutated/FISH + cell line (USPC-ARK-1) and a representative PIK3CA wild-type/FISH + cell line (USPC-ARK-2) were injected into the subcutaneous region of ten 5-8-week-old SCID mice (Harlan Laboratories, Indianapolis, IN, USA) per cell line. All animal studies were performed after receiving approval of the Institutional Animal Care and Use Committee (IACUC) of Yale University. After implantation of cells, tumours were monitored until they reached a volume of $0.1 \mathrm{~cm}^{3}$ before initiating treatment. Mice were then randomized into two treatment groups (control and trastuzumab), keeping average tumour volume similar between groups. Each group consisted of five mice. The control group was treated with vehicle (PBS), while the trastuzumab experimental group was treated with
$15 \mathrm{mg} \mathrm{kg}^{-1}$ of trastuzumab. Treatments were given intravenous (IV) once a week for 4 weeks. Tumour volume was calculated by the formula $V=$ length $\times(\text { width })^{2} \times 0.5$. Tumour sizes and body weights were recorded two times per week. The mice in both treatment groups were treated for 1 month with trastuzumab or vehicle after which they were observed for OS. When tumour reached $1 \mathrm{~cm}^{3}$ or became necrotic the animals were removed from the study and euthanized according to the rules and regulations set forth by the IACUC.

Statistical analysis. Statistical analysis was conducted using GraphPad Prism5 version 6 (GraphPad Software, Inc., San Diego, CA, USA). For each independent experiment on a given cell line, the measures of growth under different dose levels were normalised to the mean of the control group receiving no drug, so that all data were expressed as a proportion of the control. The D'Agostino \& Pearson omnibus K2 normality test was used for analysis of frequency distributions. Normalised data were then fit by nonlinear regression to a normalised logistic response curve and the resulting parameter estimates were used to calculate the value of the $\mathrm{IC}_{50}$ (in $\log 10$ units) for that experiment. For the flow cytometry experiments, changes in the phosphorylated HER2 and S6 protein levels were analysed comparing the MFI and percentage gated cells before and after the exposure to trastuzumab. ANOVA and unpaired $t$-test were used to assess pS6 and pHER2 changes and cell cycle changes in the HER2/neu overexpressing PIK3CAmutated cell line (USPC-ARK-1) and in the HER2/neu overexpressing PIK3CA wild-type cell line (USPC-ARK-2). Differences in all comparisons were considered significant at $P$-values $<0.05$.

\section{RESULTS}

PIK3CA gene mutations are common in HER2/neu gene amplified USC. Fifteen whole-exome-sequenced primary USC cell lines for which PIK3CA mutation status was known were tested for HER2 (c-erbB2) gene amplification by FISH assay. We found 7 out 15 (46\%) of the primary USC cell lines to harbour HER2/neu gene amplification. Within these cell lines four out of seven $(57 \%)$ were found to have oncogenic PIK3CA mutations. In contrast, only 2 out of 8 (25\%) of the HER $2 /$ neu not amplified cell lines were found to harbour PIK3CA mutations (Table $1, P=0.01$ ).

HER2/neu gene amplification and PIK3CA gene mutations determine response to trastuzumab. We exposed four HER2 gene amplified cell lines to different concentration of trastuzumab

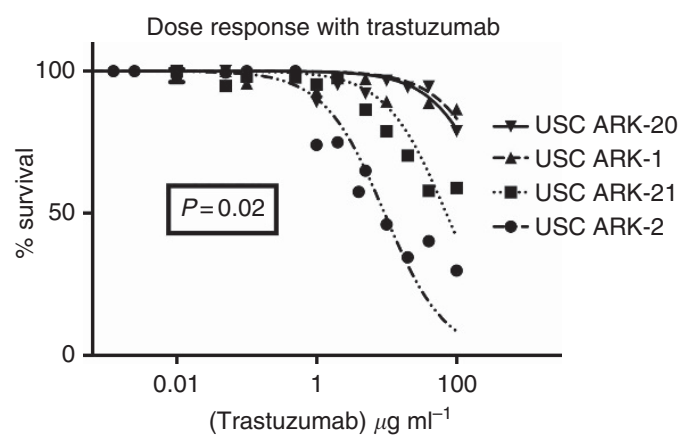

Figure 1. Effect of Trastuzumab on c-erb2 amplified cell lines with and without PIK3CA mutations. Four USC cell lines were treated with scalar concentrations of trastuzumab for 6 days before evaluating the percentage of cell survival using flow cytometry-based assays.

A statistically significant difference in resistance to trastuzumab was found in cell lines with PIK3CA mutations (USC ARK-1 and USC ARK-20) when compared with those harbouring wild-type PIK3CA (USC ARK-2 and USC ARK-21) $(P=0.02)$. 
in in vitro titration assays. As representatively shown in Figure 1, we found trastuzumab to have a consistent and significantly stronger cytostatic effect on cell lines that had overexpression of c-erbB2 and a wild-type PIK3CA gene when compared with those with overexpression of c-erbB2 and a mutated PIK3CA gene (trastuzumab $\mathrm{IC}_{50}$ mean \pm s.e.m. $=23.61 \pm 3.86$ vs $401.0 \pm 1.15 \mu \mathrm{g} \mathrm{ml}^{-1}$, $P=0.02$, respectively). Those cell lines with wild-type PIK3CA were nearly 20 -times more sensitive to trastuzumab. The ARK-2 cell line was the most sensitive to trastuzumab, with a mean inhibitory concentration $\left(\mathrm{IC}_{50}\right) \pm$ s.e.m. of $14.33 \pm 5.66 \mu \mathrm{g} \mathrm{ml}^{-1}$ followed by the ARK-21 cell line $\left(71.29 \pm 4.59 \mu \mathrm{g} \mathrm{ml}^{-1}\right)$. The least sensitive cell lines were ARK-1 with a mean inhibitory concentration $\left(\mathrm{IC}_{50}\right) \pm$ s.e.m. of $388.6 \pm 1.76 \mu \mathrm{g} \mathrm{ml}^{-1}$ and ARK-20 $\left(449.4 \pm 1.75 \mu \mathrm{g} \mathrm{ml}^{-1}\right)$. Both cell lines with low sensitivity to trastuzumab harboured hotspot mutations in the PIK3CA gene.

Trastuzumab-sensitive HER2/neu overexpressing cell lines with wild-type PIK3CA transfected with activating PIK3CA gene mutations become resistant to trastuzumab. To evaluate whether driver mutations in the PIK3CA gene may be the cause of the increased resistance of USC to trastuzumab, the HER2amplified ARK-2 cell line which harbours a wild-type PIK3CA gene, was transfected with plasmids encoding the R93Q or the H1047R PIK3CA activating mutations as well as an empty plasmid. The stably transfected cells were then exposed to different concentrations of trastuzumab in vitro. As shown in Figure 2, we found the ARK-2 cell line which was previously highly sensitive to trastuzumab, to become highly trastuzumab resistant after transfection with both the activating PIK3CA mutations with a mean inhibitory concentration $\left(\mathrm{IC}_{50}\right)$ of trastuzumab \pm s.e.m. $=$ $14.33 \pm 6.47 \mu \mathrm{g} \mathrm{ml}^{-1}$ in ARK-2 cell line with the empty plasmid $v s$ $199.2 \pm 3.28 \mu \mathrm{g} \mathrm{ml}^{-1}$ in the ARK-2 transfected cell line harbouring the R93Q PIK3CA mutation and $428.2 \pm 2.54 \mu \mathrm{g} \mathrm{ml}^{-1}$, in the ARK-2 transfected cell line harbouring the H1047R PIK3CA mutation. A one-way ANOVA comparing the $\mathrm{IC}_{50}$ between cell lines was highly significant $(P<0.0001)$. Both ARK-2 with wildtype PIK3CA and ARK-2 with the empty plasmid were equally sensitive to treatment with trastuzumab $(P=0.08)$. Both ARK-2 transfected with H1047R mutation and ARK-2 transfected with the R93Q PIK3CA mutation were significantly more resistant to treatment with trastuzumab when compared with ARK-2 with wild-type PI3KCA $(P<0.0001, P<0.0001)$. Although both of these

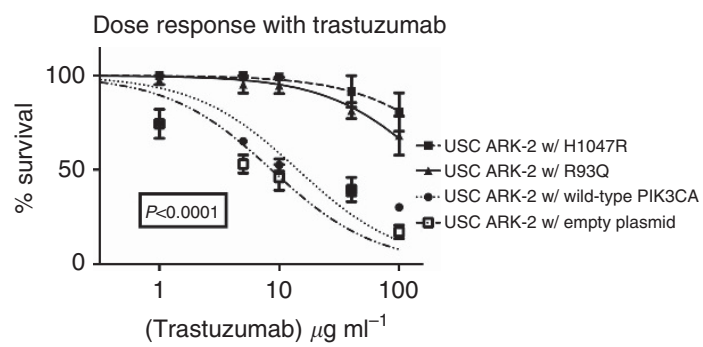

Figure 2. Effect of Trastuzumab on c-erb2 amplified USC ARK-2 cell line after transfection with plasmids encoding the oncogenic H1047R or R930 PIK3CA mutations. Briefly, after the transfection of USC ARK-2 cell line with plasmids (i.e., H1047R, R93Q, and empty plasmid) and selection with $\mathrm{G} 418$, cells were treated with scalar concentrations of trastuzumab for 6 days before evaluating the percentage of cell survival using flow cytometry-based assays. A statistically significant increase in resistance to trastuzumab was demonstrated when comparing the $\mathrm{IC}_{50}$ 's of USC ARK-2 cells transfected with the H1047 plasmid or USC ARK-2 transfected with the R930 plasmid, when compared with control USC ARK-2 cells $(P<0.0001$ and $P<0.0001$, respectively). No difference in $\mathrm{IC}_{50}$ was noted between USC ARK-2 harbouring wild-type PIK3CA and USC ARK-2 transfected with the empty control plasmid $(P=0.08)$. transfected cell lines were resistant to trastuzumab, we found a significant difference between their $\mathrm{IC}_{50}$ 's $(P=0.02)$, with the ARK-2 transfected with the H1047R mutation cell line being more resistant than the ARK-2 cell line transfected with the R93Q mutation (Figure 2).

Western blot analysis of HER2, pHER2, S6 and pS6, in PI3KCAtransfected ARK-2 USC cells. To evaluate the activation of the HER2/PI3K/mTOR pathways in USC-ARK-2 cells transfected with the H1047R and R93Q PIK3CA plasmids western blot experiments were performed. As shown in Figure 3, we were unable to detect differences in the expression levels of HER2 and pHER2 in USC-ARK-2 cells transfected with the H1047R and R93Q PIK3CA plasmids. In contrast, when S6 and pS6 expression levels were compared, we found consistent increase in the phosphorylation of S6 in the ARK-2 cells transfected with the H1047R PIK3CA plasmid when compared with the ones transfected with the R93Q PIK3CA plasmid (Figure 3).

Alterations in HER2/neu and S6 phosphorylation after treatment with trastuzumab. To gain insight into the potential molecular mechanisms causing the differential response to trastuzumab in HER2-amplified PIK3CA-mutated vs wild-type PIK3CA cell lines, we assessed the phosphorylation of HER2/neu and the phosphorylation of the downstream transcription factor S6 using flow cytometry before and after incubation with trastuzumab. For these experiments USC ARK-1 was chosen as representative PIK3CAmutated/FISH + cell line while the USC ARK-2 was selected as representative PIK3CA wild-type/FISH + cell line. As shown in Figure 4, we found a significant decrease in the phosphorylation of both HER2 and S6 after $24 \mathrm{~h}$ exposure to $40 \mu \mathrm{g} \mathrm{ml}^{-1}$ trastuzumab in both cell lines. However, when a comparison of the percent decrease in phosphorylation was performed between the PIK3CA wild-type/FISH + cell line (ARK-2) vs the PIK3CA-mutated/ $\mathrm{FISH}+$ cell line (ARK-1), a highly significant difference in the dephosphorylation of HER2 $(P=0.0007)$ and S6 phosphorylation $(P<0.0001)$ was demonstrated between the two cell lines (Figure 4).

Trastuzumab effect in vivo in xenograft models of HER2amplified USC with or without PIK3CA mutations. Over the

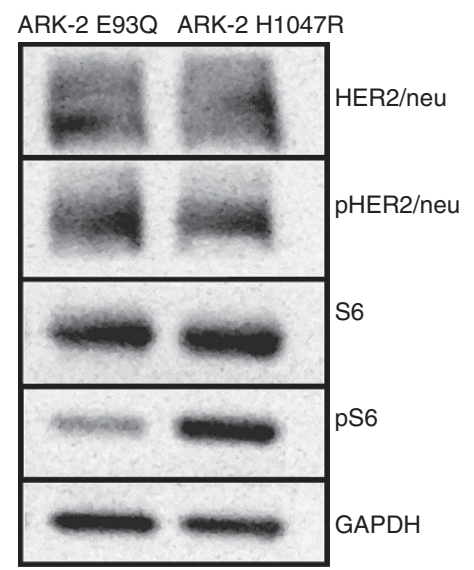

Figure 3. Expression of HER2, pHER2, S6 and pS6 in H1047R and R930 PI3KCA-transfected ARK-2 USC cells. Briefly, USPC-ARK-2 cells transfected with the plasmids encoding for the oncogenic PI3KCA mutation H1047R and R930 were grown in medium containing G418 as described in the methods section and used for western blotting analyses of HER2, pHER2, S6 and pS6. An increase in the phosphorylation of S6 in ARK-2 cells transfected with the H1047R PIK3CA plasmid when compared with ARK-2 cells transfected with the R930 PIK3CA mutation was consistent noted. Expression of GAPDH was used as loading control in all the experiments. 
course of the experiment treatment with trastuzumab was well tolerated by all the mice. As shown in Figure 5, the weekly administration of trastuzumab at $15 \mathrm{mg} \mathrm{kg}^{-1}$ induced significant tumour growth inhibition after 21 days of treatment $(P=0.001)$ and significantly improved OS $(P=0.0001)$ in the FISH + PIK3CA wild-type xenografted cell line (USPC-ARK-2) when compared with the placebo control group. In contrast, we were unable to demonstrate any significant effect of trastuzumab in the $\mathrm{FISH}+$, PIK3CA-mutated cell line (USPC-ARK-1) in terms of tumour growth inhibition $(P=0.73)$ or $\mathrm{OS}(P=0.08)$ (Figure 5$)$.

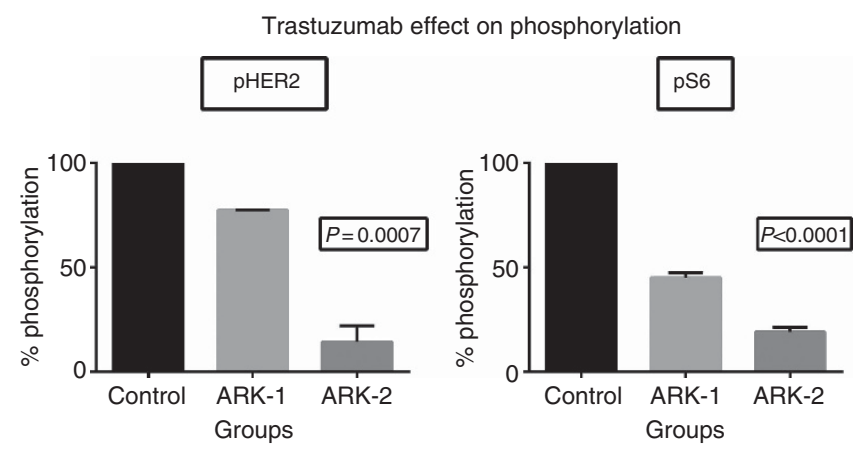

Figure 4. Effect of trastuzumab on the phosphorylation of HER2 and S6. Briefly, phosphorylation of USC ARK-1 and USC ARK-2 after $24 \mathrm{~h}$ of exposure to $40 \mu \mathrm{g} \mathrm{ml}^{-1}$ of trastuzumab when compared with untreated control cells was evaluated using a flow cytometry-based assay as described in the Methods section. The graph on the left-hand side depicts the phosphorylation of HER2 while the graph on the right hand side depicts the phosphorylation of S6. A significant decrease in the phosphorylation of both HER2 and S6 after $24 \mathrm{~h}$ exposure to $40 \mu \mathrm{g} \mathrm{ml}^{-1}$ trastuzumab was detected in both cell lines. However, when a comparison of the percent decrease in phosphorylation was performed between the PIK3CA wild-type/FISH + cell line (ARK-2) and the PIK3CA-mutated/FISH + cell line (ARK-1), a highly significant difference in the dephosphorylation of HER2 $(P=0.0007)$ and S6 phosphorylation $(P<0.0001)$ was demonstrated.

\section{DISCUSSION}

Our group has recently reported the whole exome sequencing of a large number of USC (Zhao et al, 2013). In this comprehensive study, and in agreement with data recently reported by the TCGA network in endometrial cancer, (Cancer Genome Atlas Research Network et al, 2013) a large number of USC were found to harbour HER2/Neu gene amplifications as well as oncogenic PIK3CA 'hotspot' mutations (English et al, 2013b). Accordingly, in the current study we carefully evaluated the role of PIK3CA mutations as major mechanism of resistance to trastuzumab therapy in HER2/neu overexpressing primary USC cell lines in vitro and in vivo. We found PIK3CA mutations to be significantly more common in HER2-amplified USC primary cell lines when compared with USC harbouring wild-type PIC3CA genes. These results suggest that HER2/neu gene amplified USC may be more dependent on continued PI3K/Akt/mTOR pathway activation than HER2/neu negative tumours. More importantly, the high prevalence of PIK3CA driver mutations in USC suggests that it may potentially represent one of the main mechanisms of resistance to trastuzumab-based therapy. Consistent with this view, we found HER2/neu overexpressing primary USC cell lines harbouring oncogenic PIK3CA mutations to be highly and significantly more resistant to trastuzumab when compared with HER2/neu overexpressing wild-type PIK3CA cell lines in in vitro experiments. Furthermore, in vivo treatment with trastuzumab was found to be effective in reducing tumour growth only in mouse xenografts harbouring HER2-amplified, PIK3CA wild-type USC but not in HER2-amplified, PIK3CA-mutated tumours. Finally, to unequivocally demonstrate the effect of PIK3CA mutations on trastuzumab resistance, we performed transfection experiments with plasmids encoding oncogenic PIK3CA mutations in USPC-ARK-2, a HER2/neu overexpressing whole-exome-sequenced USC cell line harbouring a wild-type PIK3CA gene. We found a consistent and significant increase in the resistance to trastuzumab after transfection of the mutated PIK3CA genes $(P=0.02)$. Of interest, the two different oncogenic mutations tested (H1047R and R93Q), which are known to confer different level of PIK3CA gene 'gain of function' in tumours, were able to confer different levels of resistance to
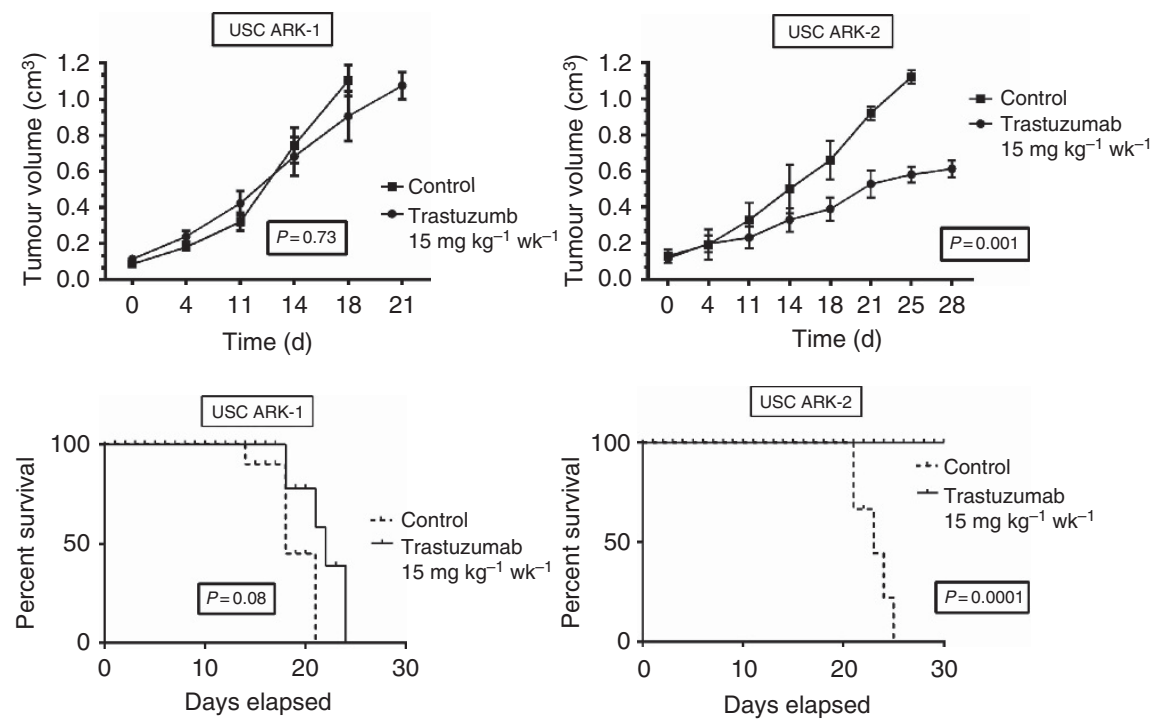

Figure 5. In vivo effect of trastuzumab in c-erb2 amplified cell lines with and without PIK3CA mutations. Tumour growth and OS of mice harbouring USC ARK-1 (i.e., HER2-amplified/PIK3CA-mutated cell line, left panel) and USC ARK-2 (i.e., HER2-amplified/PIK3CA wild-type cell line, right panel) after treatment with trastuzumab $\left(15 \mathrm{mg} \mathrm{kg}^{-1} \mathrm{wk}^{-1}\right)$. No significant difference in tumour growth inhibition $(P=0.73)$ or OS $(P=0.08)$ was detected in the ARK-1 group of mice when compared with control after trastuzumab treatment. In contrast, a statistically significant difference in tumour growth inhibition $(P=0.001)$ and OS $(P<0.0001)$ was detected in the ARK-2 group of mice treated with trastuzumab. 
trastuzumab (Rudd et al, 2011). Consistent with these results, USCARK-2 cells transfected with the H1047R mutation demonstrated higher levels of phosphorylation of S6 when compared with ARK-2 cells transfected with the R93Q PIK3CA plasmids by western blot. These results suggesting increased PI3kinase downstream pathway signalling in the H1047R transduced cells.

Overexpression of HER2/neu is associated with aggressive disease and poor prognosis in multiple human tumours including USC (Berchuck et al, 1990, 1991; Santin et al, 2005; Iqbal and Iqbal, 2014). Many previous studies have investigated HER2 overexpression and/or gene amplification in endometrial cancer patients. In GOG181B, in which 286 advanced or recurrent endometrial carcinomas were screened for HER2 overexpression, only $7 \%$ of endometrioid tumours were HER2-amplified, compared with $28 \%$ of serous cancers (English et al, 2013c). In GOG-177, 234 specimens representing advanced or recurrent endometrial cancer were available for immunohistochemistry (IHC) and 182 for fluorescence in situ hybridisation. Of these, $11 \%$ of grade 3 endometrioid and $21 \%$ of serous tumours demonstrated HER2 gene amplification by FISH (English et al, 2013c). The proportion of overexpression by IHC was significantly higher in serous vs nonserous histologies (61\% vs $41 \%, P=0.03)$. Finally, in a study of 85 pure serous carcinomas and 23 mixed endometrial carcinomas with serous component identified over a 4 -year period at Yale University, Buza et al (2014) found that 35\% exhibited HER2 $3+$ overexpression and/or gene amplification. Taken together these results suggest that HER2 may represent a relevant molecular target in endometrial cancer patients, in particular against biologically aggressive USC.

Although the identification of USC harbouring amplification of the $E r b B 2$ gene by FISH may represent the most effective way to guide selection of USC patients who may benefit more from trastuzumab therapy, in selected endometrial cancer patients, single agent anti-HER2 directed therapy has so far failed to produce meaningful responses in clinical trials (Fleming et al, 2010). Although clinical trials with trastuzumab in combination with carboplatin-paclitaxel chemotherapy are currently ongoing in USC (NCT01367002), these disappointing results strongly suggest an innate or rapidly acquired drug-induced resistance to antiHER2-targeted therapy (Fleming et al, 2010). Unfortunately, scant information is currently available regarding the potential mechanisms of resistance to anti-HER2 monoclonal antibody operative in endometrial cancer patients. To fill this gap in knowledge, our group has recently reported elevated expression levels of the extracellular domain of HER2 both in the supernatant of HER2amplified USC cell lines in vitro as well as in the plasma of USC patients in vivo (Todeschini et al, 2011). These data suggest that, similarly to what has been demonstrated in a subset of breast cancers, the proteolytic cleavage of full-length HER2 with the formation of a cell surface-associated fragment (p95HER2), which lacks the trastuzumab-binding domain of the full-length HER2, may represent an important mediator of trastuzumab resistance in USC patients (Pupa et al, 1993; Christianson et al, 1998; Codony-Servat et al, 1999). Moreover, in a recent review of a large series of USC specimens tested for HER2 overexpression in our institution we found a marked heterogeneity in HER2 overexpression (i.e., $53 \%$ of the HER2 overexpressed/amplified tumours harboured a significant intra-tumoural heterogeneity in HER2 protein expression) (Buza et al, 2014). These results highlighting potential differences in HER2 expression in endometrial cancers $v s$ breast cancers with a significant negative impact on the efficacy of HER2-targeted treatments.

The activation of downstream HER2 effectors may also lead to primary anti-HER2 therapy resistance. Accordingly, in vitro studies have identified phosphatidylinositol 3-kinase (PI3K) expression, low PTEN expression, AKT phosphorylation and S6K phosphorylation as potential mediators of primary trastuzumab resistance in breast cancer cell lines (Kataoka et al, 2010; O'Brien et al, 2010). In this regard, while in normal cells the PIK3CA/AKT/ mTOR pathway is tightly controlled, a large number of human cancers including endometrial tumours may harbour PIK3CA mutations which result in the deregulated activation of the pathway and the ability of tumours to metastasise and invade normal tissues, continue to grow under conditions of low nutrients or low oxygen, and resist radiation and chemotherapy treatment (Brachmann et al, 2009; English et al, 2013c).

In conclusion, we demonstrated that oncogenic PIK3CA mutations in HER2/neu overexpressing USC are common and may constitute a major mechanism of resistance to trastuzumab. Importantly, PIK3CA may represent a biomarker able to identify patients unlikely to respond to single agent trastuzumab-based therapy. Novel HER2/neu targeted agents effective in the treatment of trastuzumab-resistant human tumours (i.e., T-DM1 and/or afatinib) (English et al, 2014d, Schwab et al, 2014) may represent novel, more effective strategies against this subset of biologically aggressive endometrial cancers.

\section{ACKNOWLEDGEMENTS}

This work was supported in part by R01 CA154460-01 and U01 CA176067-01A1 grants from NIH, the Deborah Bunn Alley Foundation, the Tina Brozman Foundation, the Discovery to Cure Foundation and the Guido Berlucchi Foundation to ADS. This investigation was also supported by NIH Research Grant CA-16359 from the NCI.

\section{CONFLICT OF INTEREST}

The authors declare no conflict of interest.

\section{REFERENCES}

Arnould L, Gelly M, Penault-Llorca F, Benoit L, Bonnetain F, Migeon C, Cabaret V, Fermeaux V, Bertheau P, Garnier J, Jeannin J-F, Coudert B (2006) Trastuzumab-based treatment of HER2-positive breast cancer: an antibody-dependent cellular cytotoxicity mechanism? Br J Cancer 94: 259-267.

Berchuck A, Kamel A, Whitaker R, Kerns B, Olt G, Kinney R, Soper JT, Dodge R, Clarke-Pearson DL, Marks P (1990) Overexpression of HER-2/neu is associated with poor survival in advanced epithelial ovarian cancer. Cancer Res 50: 4087-4091.

Berchuck A, Rodriguez G, Kinney RB, Soper JT, Dodge RK, Clarke-Pearson DL, Bast Jr RC (1991) Overexpression of HER-2/neu in endometrial cancer is associated with advanced stage disease. Am J Obstet Gynecol 164: $15-21$.

Bokhman JV (1983) Two pathogenetic types of endometrial carcinoma. Gynecol Oncol 15: 10-17.

Brachmann SM, Hofmann I, Schnell C, Fritsch C, Wee S, Lane H, Wang S, Garcia-Echeverria C, Maira S-M (2009) Specific apoptosis induction by the dual PI3K/mTor inhibitor NVP-BEZ235 in HER2 amplified and PIK3CA mutant breast cancer cells. Proc Natl Acad Sci USA 106: 22299-22304.

Buza N, Roque DM, Santin AD (2014) HER2/neu in endometrial cancer: a promising therapeutic target with diagnostic challenges. Arch Pathol Lab Med 138: 343-350.

Cancer Genome Atlas Research NetworkKandoth C, Schultz N, Cherniack AD, Akbani R, Liu Y, Shen H, Robertson AG, Pashtan I, Shen R, Benz CC, Yau C, Laird PW, Ding L, Zhang W, Mills GB, Kucherlapati R, Mardis ER, Levine DA (2013) Integrated genomic characterization of endometrial carcinoma. Nature 497: 67-73.

Christianson TA, Doherty JK, Lin YJ, Ramsey EE, Holmes R, Keenan EJ, Clinton GM (1998) NH2-terminally truncated HER-2/neu protein: 
relationship with shedding of the extracellular domain and with prognostic factors in breast cancer. Cancer Res 58: 5123-5129.

Codony-Servat J, Albanell J, Lopez-Talavera JC, Arribas J, Baselga J (1999) Cleavage of the HER2 ectodomain is a pervanadate-activable process that is inhibited by the tissue inhibitor of metalloproteases-1 in breast cancer cells. Cancer Res 59: 1196-1201.

Dancey JE (2006) Therapeutic targets: MTOR and related pathways. Cancer Biol Ther 5: 1065-1073.

English DP, Roque D, Carrara L, Lopez S, Bellone S, Cocco E, Bortolomai I, Schwartz PE, Rutherford T, Santin AD (2013a) HER2/neu gene amplification determines the sensitivity of uterine serous carcinoma cell lines to AZD8055, a novel dual mTORC1/2 inhibitor. Gynecol Oncol 131: 753-758.

English DP, Bellone S, Cocco E, Bortolomai I, Pecorelli S, Lopez S, Silasi D-A, Schwartz PE, Rutherford T, Santin AD (2013b) Oncogenic PIK3CA gene mutations and HER2/neu gene amplifications determine the sensitivity of uterine serous carcinoma cell lines to GDC-0980, a selective inhibitor of Class I PI3 kinase and mTOR kinase (TORC1/2). Am J Obstet Gynecol 209: 465.e1-9.

English DP, Roque DM, Santin AD (2013c) HER2 expression beyond breast cancer: therapeutic implications for gynecologic malignancies. Mol Diagn Ther 17: 85-99.

English DP, Bellone S, Schwab CL, Bortolomai I, Bonazzoli E, Cocco E, Buza N, Hui P, Lopez S, Ratner E, Silasi DA, Azodi M, Schwartz PE, Rutherford TJ, Santin AD (2014d) T-DM1, a novel antibody-drug conjugate, is highly effective against primary HER2 overexpressing uterine serous carcinoma in vitro and in vivo. Cancer Med 3: 1256-1265.

Fleming GF, Sill MW, Darcy KM, McMeekin DS, Thigpen JT, Adler LM, Berek JS, Chapman JA, DiSilvestro PA, Horowitz IR, Fiorica JV (2010) Phase II trial of trastuzumab in women with advanced or recurrent, HER2-positive endometrial carcinoma: a Gynecologic Oncology Group study. Gynecol Oncol 116: 15-20.

Le Gallo M, O'Hara AJ, Rudd ML, Urick ME, Hansen NF, O'Neil NJ, Price JC, Zhang S, England BM, Godwin AK, Sgroi DC. NIH Intramural Sequencing Center (NISC) Comparative Sequencing ProgramHieter P, Mullikin JC, Merino MJ, Bell DW (2012) Exome sequencing of serous endometrial tumors identifies recurrent somatic mutations in chromatinremodeling and ubiquitin ligase complex genes. Nat Genet 44: 1310-1315.

Gennari R, Menard S, Fagnoni F, Ponchio L, Scelsi M, Tagliabue E, Castiglioni F, Villani L, Magalotti C, Gibelli N, Oliviero B, Ballardini B, Da Prada G, Zambelli A, Costa A (2004) Pilot study of the mechanism of action of preoperative trastuzumab in patients with primary operable breast tumors overexpressing HER2. Clin Cancer Res 10: 5650-5655.

Goff BA (2005) Uterine papillary serous carcinoma: what have we learned over the past quarter century? Gynecol Oncol 98: 341-343.

Hamilton CA, Cheung MK, Osann K, Chen L, Teng NN, Longacre TA, Powell MA, Hendrickson MR, Kapp DS, Chan JK (2006) Uterine papillary serous and clear cell carcinomas predict for poorer survival compared to grade 3 endometrioid corpus cancers. Br J Cancer 94: 642-646.

Hynes NE, Stern DF (1994) The biology of erbB-2/neu/HER-2 and its role in cancer. Biochim Biophys Acta 1198: 165-184.

Iqbal N, Iqbal N (2014) Human epidermal growth factor receptor 2 (HER2) in cancers: overexpression and therapeutic implications. Mol Biol Int 2014: 852748.

Kataoka Y, Mukohara T, Shimada H, Saijo N, Hirai M, Minami H (2010) Association between gain-of-function mutations in PIK3CA and resistance to HER2-targeted agents in HER2-amplified breast cancer cell lines. Ann Oncol 21: 255-262.

Morrison C, Zanagnolo V, Ramirez N, Cohn DE, Kelbick N, Copeland L, Maxwell GL, Maxwell LG, Fowler JM (2006) HER-2 is an independent prognostic factor in endometrial cancer: association with outcome in a large cohort of surgically staged patients. J Clin Oncol 24: 2376-2385.

Okines A, Cunningham D, Chau I (2011) Targeting the human EGFR family in esophagogastric cancer. Nat Rev Clin Oncol 8: 492-503.

O'Brien NA, Browne BC, Chow L, Wang Y, Ginther C, Arboleda J, Duffy MJ, Crown J, O’Donovan N, Slamon DJ (2010) Activated phosphoinositide
3-kinase/AKT signaling confers resistance to trastuzumab but not lapatinib. Mol Cancer Ther 9: 1489-1502.

Peiro G, Mayr D, Hillemanns P, Löhrs U, Diebold J (2004) Analysis of HER-2/neu amplification in endometrial carcinoma by chromogenic in situ hybridization. Correlation with fluorescence in situ hybridization, HER-2/neu. Mod Pathol. 17: 227-287.

Pupa SM, Ménard S, Morelli D, Pozzi B, De Palo G, Colnaghi MI (1993) The extracellular domain of the c-erbB-2 oncoprotein is released from tumor cells by proteolytic cleavage. Oncogene 8: 2917-2923.

Rudd ML, Price JC, Fogoros S, Godwin AK, Sgroi DC, Merino MJ, Bell DW (2011) A unique spectrum of somatic PIK3CA (p110alpha) mutations within primary endometrial carcinomas. Clin Cancer Res 17: 1331-1340.

Santin AD, Bellone S, Van Stedum S, Bushen W, Palmieri M, Siegel ER, De Las Casas LE, Roman JJ, Burnett A, Pecorelli S (2005) Amplification of c-erbB2 oncogene: a major prognostic indicator in uterine serous papillary carcinoma. Cancer 104: 1391-1397.

Schwab C, Bellone S, English DP, Roque DM, Lopez S, Cocco E, Nicoletti R, Bortolomai I, Bonazzoli E, Ratner E, Silasi DA, Azodi M, Schwartz PE, Rutherford TJ, Santin AD. Afatinib demonstrates remarkable activity against HER2-amplified uterine serous endometrial cancer in vitro and in vivo. Br J Cancer (2014) 111: 1750-1756.

She Q-B, Chandarlapaty S, Ye Q, Lobo J, Haskell KM, Leander KR, DeFeo-Jones D, Huber HE, Rosen N (2008) Breast tumor cells with PI3K mutation or HER2 amplification are selectively addicted to Akt signaling. PLoS One 3: e3065.

Siegel RL, Miller KD, Jemal A (2015) Cancer Statistics, 2015. CA Cancer J Clin 65: 5-29.

Slamon DJ, Leyland-Jones B, Shak S, Fuchs H, Paton V, Bajamonde A, Fleming T, Eiermann W, Wolter J, Pegram M, Baselga J, Norton L (2001) Use of chemotherapy plus a monoclonal antibody against HER2 for metastatic breast cancer that overexpresses HER2. N Engl J Med 344: 783-792.

Thomas M, Mariani A, Wright JD, Madarek EOS, Powell MA, Mutch DG, Podratz KC, Dowdy SC (2008) Surgical management and adjuvant therapy for patients with uterine clear cell carcinoma: a multi-institutional review. Gynecol Oncol 108: 293-297.

Todeschini P, Cocco E, Bellone S, Varughese J, Lin K, Carrara L, Guzzo F, Buza N, Hui P, Silasi D-A, Ratner E, Azodi M, Schwartz PE, Rutherford TJ, Pecorelli S, Santin AD (2011) Her2/neu extracellular domain shedding in uterine serous carcinoma: implications for immunotherapy with trastuzumab. Br J Cancer 105: 1176-1182.

Verma S, Miles D, Gianni L, Krop IE, Welslau M, Baselga J, Pegram M, Oh D-Y, Diéras V, Guardino E, Fang L, Lu MW, Olsen S, Blackwell K. EMILIA Study Group (2012) Trastuzumab emtansine for HER2-positive advanced breast cancer. $N$ Engl J Med 367: 1783-1791.

Villella JA, Cohen S, Smith DH (2006) HER2/neu overexpression in uterine papillary serous cancers and its possible therapeutic implications. Int J Gynecol Cancer 16: 1897-1902.

Yoon J-H, Yoo S-C, Kim WY, Chang S-J, Chang K-H, Ryu H-S (2010) Para-aortic lymphadenectomy in the management of preoperative grade 1 endometrial cancer confined to the uterine corpus. Ann Surg Oncol 17: 3234-3240.

Zhao S, Choi M, Overton JD, Bellone S, Roque DM, Cocco E, Guzzo F, English DP, Varughese J, Gasparrini S, Bortolomai I, Buza N, Hui P, Abu-Khalaf M, Ravaggi A, Bignotti E, Bandiera E, Romani C, Todeschini P, Tassi R, Zanotti L, Carrara L, Pecorelli S, Silasi DA, Ratner E, Azodi M, Schwartz PE, Rutherford TJ, Stiegler AL, Mane S, Boggon TJ, Schlessinger J, Lifton RP, Santin AD (2013) Landscape of somatic single-nucleotide and copy-number mutations in uterine serous carcinoma. Proc Natl Acad Sci USA 110: 2916-2921.

This work is published under the standard license to publish agreement. After 12 months the work will become freely available and the license terms will switch to a Creative Commons AttributionNonCommercial-Share Alike 4.0 Unported License. 